\title{
BASES DEL ANTIPARLAMENTARISMO MILITAR ESPAÑOL (1874-1898)
}

\author{
POR \\ FRANCISCO J. VANACLOCHA \\ Departamento de Derecho Político Español \\ Facultad de Ciencias Políticas. Universidad Complutense
}

\begin{abstract}
«Lo que nos salva es la eficiencia, la devoción a la eficiencia. Pero aquellos muchachos en realidad no valían mucho».
\end{abstract}

(Joseph Conrad, El corazón de las tinieblas.)

El antiparlamentarismo del Ejército español en el siglo xx es un fenómeno cuya constatación no entraña apenas dificultades. Pero analizar los elementos que contribuyeron a configurar en nuestro Ejército un sistema de actitudes político-ideológicas que rechazara la legitimidad y operatividad de las instituciones parlamentarias es ya un tema extremadamente complejo. En cualquier caso, las bases del antiparlamentarismo militar del presente siglo se pueden encontrar en el último cuarto del siglo xIx, en la primera mitad de la Restauración o, mejor dicho, en el período en el que el sistema político de la Restauración vive aún un proceso de configuración y consolidación, desde sus orígenes (1874-75) hasta su primera gran crisis (1898) ${ }^{1}$.

\section{LOS ORGANOS DE OPINION MILITAR}

Para estudiar la actitud del Ejército de la Restauración ante cualquiera de las dimensiones del sistema político ha de acudirse fundamentalmente a la prensa político-militar de la época, puesto que constituye la fuente que refleja con mayor fidelidad la opinión política del colectivo militar ${ }^{2}$.

${ }^{1}$ El presente artículo se ha extraído de una parte de un capítulo del trabajo titulado La opinión militar española ante el sistema político (1874-1898), presentado como tesis doctoral en la Facultad de Ciencias Políticas y Sociología, Madrid, 1980, y para cuya elaboración contó el autor con una beca de investigación concedida en 1977 por la Fundación Juan March, dentro de la sección de Ciencias Sociales.

${ }_{2}$ Cfr. nuestra tesis doctoral La opinión militar española... 
A través de tres títulos esencialmente $-E l$ Correo Militar (conservador), La Correspondencia Militar (representante de lo que podemos denominar un radicalismo militar-burgués, fluctuante en cuanto a sus preferencias partidistas) y El Ejército Español (liberal-fusionista)—, dicho tipo de prensa (verdaderamente política y verdaderamente castrense) alcanza una importancia objetiva en el contexto periodístico, político y militar de la Restauración. No sólo alcanzaría una notable audiencia e influencia entre el público militar, sino que su opinión sería tenida muy en cuenta por los periódicos más importantes del país, por los Gobiernos y las altas instancias de los departamentos de Guerra y Marina, por los senadores y diputados, por los partidos políticos, etcétera. Sus artículos llegarían a originar algunas veces situaciones políticas extremadamente conflictivas.

Independientemente de las funciones que cada uno de los periódicos político-militares pretendiera asumir, lo cierto es que reflejaron las principales corrientes legales de opinión militar y político-militar y que asimismo la prensa político-militar en su conjunto pulsó y representó mejor que ningún otro sector o institución castrense la opinión del Ejército durante la Restauración. Opinión militar y prensa político-militar (mejor dicho, opinión de la prensa políticomilitar globalmente considerada) pueden ser utilizadas, pues, como términos equivalentes - $\mathrm{y}$ así lo hacemos en el presente artículo- sin incurrir en error alguno.

\section{ARGUMENTOS MILITARES CONTRA LAS CORTES}

El régimen de la Restauración buscó desde sus comienzos configurarse a partir de una legitimidad dinástica de orden tradicional y a la vez sobre una legitimidad liberal-representativa sustentada en procesos electorales periódicos. Se recurriría con prontitud, pues, a un sistema parlamentario-representativo que pretendería ser consecuente con la historia española y con el contexto europeo, esto es, a unas Cortes en las que estuvieran presentes los partidos que formalmente representaran las opiniones e intereses de la nación y que controlaran y compartieran el poder político ${ }^{3}$.

Pese a todo, el antiparlamentarismo de la opinión militar afloraría repetidamente entre 1875 y 1898 , creciendo con el transcurso de los años, alimentado por cuatro tipos de argumentos fundamentalmente:

- La falta de legitimidad de origen de las Cortes, es decir, el ser fruto de unos procesos electorales manipulados y fraudulentos, con resultados fabricados prácticamente por el Gobierno de turno.

- La ineficacia de las Cámaras para ofrecer soluciones legislativas a la problemática militar $\mathrm{y}$, por extensión, a los problemas fundamentales del país.

- No hallarse representados en las Cortes los intereses del Ejército.

${ }^{3}$ Cfr. especialmente Miguel Martínez Cuadrado, La burguesía conservadora (1874-1931), Alianza Editorial, Madrid, 1973, págs. 12 y sigs., y 369 y sigs. 
- El carácter fragmentador, egoísta y antipatriótico de la actuación parlamentaria (y no parlamentaria) de los políticos y partidos presentes en las Cortes.

\section{LA OPINION MILITAR ANTE LA PRACTICA ELECTORAL}

Los fraudes y manipulaciones electorales fueron sobradamente conocidos por la opinión pública en tiempos de la Restauración. Casi nadie se atrevió a negarlos y ya se encargaron de sacarlos a la luz los órganos de prensa de las formaciones políticas perjudicadas. Los periódicos militares tampoco cerrarían los ojos a la evidencia. Muy pocas veces se mostrarían convencidos de la «sinceridad» de una consulta electoral; por el contrario, reconocerían repetidamente que «el Gobierno dispon(ía) siempre de medios para salir victorioso» ${ }^{4}$, no disimulando su escepticismo ante las esporádicas circulares oficiales que recomendaban a las autoridades administrativas de algún departamento ministerial el estricto cumplimiento de la legalidad.

Precisemos, sin embargo, que la prensa político-militar esgrimiría como arma política las prácticas que habitualmente desvirtuaban el sufragio, aireándolas para atacar al partido en el poder o silenciándolas cuando se defendían las posiciones del Gobierno, recurriendo entonces al conocido «más son los otros». Muy excepcionalmente, razones políticas llevarian a alguno de estos periódicos a justificar incluso que el Gobierno dirigiera las elecciones y confeccionara sus resultados, considerándolo un mal necesario ${ }^{5}$.

De todos modos, las prácticas electorales nunca entusiasmaron a la opinión militar; más bien todo lo contrario. Y no fue sólo la habitual y reconocida práctica del «pucherazo» lo que determinó tal actitud (independientemente de la participación o no de los elementos militares), sino el carácter de determinadas actividades o implicaciones que traían consigo los comicios, tanto su contexto eminentemente clientelista, aparte del fenómeno de la afloración e intensificación del caciquismo puro y simple, como asimismo el paréntesis de abierto partidismo que imponían en la política nacional durante un período determinado de tiempo.

Ya en marzo de 1875 , muy tempranamente, El Correo Militar no veía con buenos ojos el entramado de «ofrecimientos y compromisos propios de épocas de elecciones» ${ }^{6}$. Y en efecto, la crítica y ridiculización del sistema clientelista sería ejercida constantemente por la prensa militar, si bien las

${ }^{4}$ El Correo Militar, 4 de mayo de 1895. Digamos, sin embargo, que frases como la citada se repiten constantemente en todos los periódicos militares.

5 Así lo diría El Correo Militar de 13 de abril de 1896 en su artículo «Lo de ayer»: «Si aquí algún Gobierno dejase de dirigir las elecciones, no por eso se cometerían menos abusos, sino más, muchos más. Los caciques apretarían de firme a favor del candidato que más les diese u ofreciera, y veríamos los mismos amaños y chanchullos que hoy, sólo que cometidos en favor del candidato blanco, negro o azul, viniendo todo a constituir un pugilato de fuerza bruta entre los muñidores de la elección.

Y como resultado de todo esto serían las Cámaras en absoluto ingobernables; o mejor dicho, no se podría gobernar con ellas el país.»

64 de marzo de 1875 . 
propias preferencias políticas dictarían el momento de hacerla e incluso la defensa eventual de determinadas relaciones de este tipo ${ }^{7}$.

Ciertamente, se llegó a contraponer las elecciones a la satisfacción de las necesidades del país. Alguna vez se acusó al Gobierno de sufragar los gastos electorales del partido en el poder con dinero procedente de algunas partidas de los presupuestos del Estado, y en concreto de la caja de Ultramar. Cuando en 1890 se tuvo que elaborar un nuevo censo electoral, la prensa militar consideró inútil el tiempo y los gastos que se invertían en ello, mostrando así la poca estima que le merecían las consultas electorales.

La reimplantación del sufragio universal no modificó el mal concepto de los periódicos militares sobre las elecciones, ni siquiera el de aquellos no canovistas que habían depositado en aquél sus esperanzas de que cambiaran las expectativas ciudadanas, incluidas las del colectivo militar ${ }^{8}$. Se daba por hecho que funcionarían regularmente los mecanismos clientelistas ${ }^{9}$, cuando no los fraudulentos.

No obstante, la elección de 1891 despertaría el interés de la opinión castrense. La novedad del voto de los militares y la posibilidad de que la ampliación del sufragio arrojara resultados contrarios al Gobierno habían abierto un margen de incertidumbre. Pero los resultados de las elecciones de los años noventa confirmarían que el voto popular no derribaba Gobiernos. «La máquina electoral ha funcionado con la misma pasmosa regularidad con que funcionaba antes con el sufragio restringido», diría El Ejército Español, añadiendo: «y luego hay quien se extraña de la apatía de los electores» ${ }^{10}$.

${ }^{7} \mathrm{La}$ relación de clientela existente entre el partido en el Gobierno y las asociaciones de clases pasivas, en las que los jefes y oficiales retirados del Ejército desarrollaban una notable actividad, fue seguida con particular interés por los periódicos militares, cuya mayor o menor proximidad al Gobierno que convocaba las elecciones les marcaba su respectiva defensa o crítica de dicho clientelismo.

${ }^{8}$ El Ejército Español llega a hacer suyo el lema «Un hombre, un voto, un fusil», con* siderando que el sufragio universal era el primer paso para la implantación del sufragio universal (véase 2 de diciembre de 1888).

9 Veamos el significativo razonamiento de La Correspondencia Militar de 21 de enero de 1891:

«Esos miles de electores madrileños tienen cada cual su ocupación intelectual o mecánica; dependen, más o menos, de alguien, pues sumamente escasa será, de seguro, la cifra de los que gocen absoluta independencia. Hoy permanecen al margen de una contienda en la que creen (erróneamente) que nada les va ni les viene, así es que se apartan de todo ese ficticio movimiento sostenido por los candidatos y sus gentes; pero el día de la elección irán poco menos que a la fuerza a las urnas, allá donde los mande o los conduzca el que sobre ellos ejerce autoridad o influencia.

Los empleados, donde el Gobierno los envíe; los cesantes de la fusión, allá donde Sagasta prevenga, y los demás, el comerciante, el industrial, el propietario, allí donde logre conducirles el que mayor presión moral (o aún material) haga sobre ellos.

De aquí que todos muy tranquilos permanezcan en su casa o en su tienda o en su oficina esperando al jefe o al patrón, o al acreedor o al amigo que les ha de poner en la mano la candidatura, la que sin abrir quizá, y tal vez sin leerla, llevarán a la urna, sin preocuparse ni antes ni después de lo que allí saliere.

Añádase a esto la masa de desgraciados sobre los que se ejercerá además de la influencia antedicha, la suculenta de un café, o la más aromática de un puro, o la no menos sólida unas cuantas pesetas, y se tendrá idea de cómo a pesar de que voten muchos, no significará esto la menor dosis de entusiasmo.»

${ }^{10}$ El Ejército Español, 3 de febrero de 1891. 
Desde luego, entre los periódicos militares siempre habría alguno, cuando no todos, que pusieran en duda la validez social de la celebración de elecciones, en base al argumento del gran abstencionismo existente. En efecto, la abstención electoral alcanzó durante el último cuarto del siglo xIX tasas muy elevadas no inferiores jamás a la tercera parte del electorado; la prensa militar - como la no militar - las cifraría en la mitad o en las dos terceras partes del censo ${ }^{11}$. Aireado en su momento por unos u otros periódicos militares, constituiría uno de los argumentos favoritos para negar el carácter representativo a las Cortes así elegidas, más aún cuando se daba por supuesta la buena disposición del pueblo español para el ejercicio del voto, un pueblo al que tanto le había costado - se decía- consolidar el régimen constitucional ${ }^{12}$. Resultaría insólito encontrar en las páginas de la prensa político-militar una crítica de quienes se abstenían, mientras proliferarían, por el contrario, las interpretaciones comprensivas hacia tal actitud. Pero si se la justificaba, también se buscaba a los culpables, y se les encontraba, claro está: los políticos eran los únicos culpables ante la opinión militar ${ }^{13}$.

De forma un tanto tangencial, llegó a criticarse también la representación surgida de un sistema electoral mayoritario sobre la base de que podía originar que un partido minoritario, en razón del número de votos obtenido, alcanzara la mayoría parlamentaria. Pero aquello no dejaba de ser todavía sino un tema exótico en la España de la época ${ }^{14}$.

Las convocatorias de elecciones generales a Cortes de 1896 y 1898 , celebradas en momentos verdaderamente críticos para España, deterioraron todavía más la imagen de las consultas electorales a ojos del Ejército. La prensa militar las mostraría como un rito que sólo beneficiaba a la clase política en lucha continua por el poder y al margen, o aun en contra, como en aquellas ocasiones, de los intereses generales del país. Si en 1896 sería El Ejército Español el que reflejara esta opinión (en contra del Gobierno conservador, como siempre), en 1898, al filo del desastre colonial, serían los dos periódicos conservadores ( $E l$ Correo Militar y La Correspondencia Militar, en contra del Gobierno de Sagasta) los que se indignaran ante la convocatoria electoral.

${ }^{11}$ Véase, en concreto, La Correspondencia Militar, 7 de febrero de 1891, y El Ejército Español, 3 de febrero de 1891.

${ }_{12}$ Así opinaba El Ejército Español («La indiferencia en materia electoral», 4 de diciembre de 1889):

«Pocos países mejor dispuestos que el nuestro al ejercicio del voto. Aquí el sistema constitucional está arraigado en lo más hondo del pueblo, que lo ha conquistado en lucha tenaz y decidida, comprando su conquista con torrentes de sangre y de dinero, durante una guerra funesta de siete años, asegurándola luego a mayor costa aún en otra guerra no menos larga y no menos fatal que la primera...»

${ }_{13}$ El Ejército Español («La indiferencia en materia electoral», 4 de diciembre de 1889) afirmaba con rotundidad:

«No nos quejemos, pues, del cuerpo electoral. Los gobernantes hacen a los pueblos a su imagen y semejanza. Políticos sin fe, forzosamente tienen que hacer un pueblo indiferente y falto de ideales.»

${ }^{14}$ Véase La Correspondencia Militar, 7 de febrero de 1891. En aquellas fechas, la prensa de Madrid prestó un momentáneo interés por el tema. 


\section{LA ILUSION DE LA REPRESENTACION MILITAR EN CORTES.}

\section{LA TENTACION CORPORATIVISTA}

La práctica parlamentaria española había consagrado durante el siglo xIX el derecho de los militares a ocupar escaños en las Cortes. Durante la Restauración, la presencia del elemento castrense en las Cámaras coadyuvaría considerablemente a institucionalizar el poder militar; las personalidades del Ejército más brillantes y con mayor vocación política encontrarían allí el lugar donde satisfacerla, sin que ello implicara riesgos para el régimen político.

La Constitución de 1876 aseguraba la presencia en el Senado de altas jerarquías del Ejército y la Armada por razón de su cargo o por nombramiento real con carácter vitalicio, de acuerdo con una lógica peculiar de institucionalización corporativa ${ }^{15}$. Estos senadores debían ser en principio los encargados de representar en las Cortes a la institución militar, independientemente de los resultados que arrojaran las elecciones al Senado y al Congreso. Respondiendo a la concepción clásica de que el Ejército debe ser representado por vía jerárquica, se establecía que en todo caso los militares senadores tenían que pertenecer al generalato.

Sin embargo, la atención de la prensa político-militar se centraría esencialmente en la función representativa del militar elegido parlamentario. La existencia en sucesivas legislaturas de un buen número de militares elegidos diputados y senadores (rondaría normalmente la treintena) restaría importancia a la representación institucional-corporativa del Ejército a través de senadores natos y vitalicios, aunque de ninguna forma se la despreciaría ${ }^{16}$.

La opinión militar entendía que el parlamentario que vestía el uniforme tenía el deber, totalmente compatible con el ejercicio de la representación nacional, de trabajar en favor de la corporación castrense de todas las formas posibles. Especialmente, habría de influir en la labor legislativa de las Cámaras «en apoyo de saludables reformas» - se decía- que tendieran al «perfeccionamiento de la fuerza armada» ${ }^{17}$. Una idea lógica ésta, si se piensa que el primer argumento que se esgrimía para justificar la presencia de militares en las Cortes, era que sin su concurso no podían ni debían elaborarse ciertas leyes. Al fin y al cabo, el militar no podía dejar de ser militar ni de estar sujeto por lazos de compañerismo, seguiría razonando la prensa político-militar.

${ }^{15}$ Los capitanes generales del Ejército y el almirante de la Armada eran «senadores por derecho propio» según la Constitución de 30 de junio de 1876 (artículo 21), como asimismo el presidente del Consejo Supremo de la Guerra y la Armada, después de dos años de ejercicio en el cargo. Por otra parte, podían ser senadores vitalicios nombrados por la Cotona, los tenientes generales del Ejército y vicealmirantes de la Armada, después de dos años de su nombramiento, y los consejeros del Tribunal Supremo de la Guerra y la Armada; todos ellos deberían además disfrutar de una renta de 7.500 pesetas, procedente de bienes propios o de sueldos de empleos que no pudieran perderse sino por causa legalmente probada, o de jubilación, retiro o cesantía (artículo 22).

${ }^{16}$ Por ejemplo, cuando se tratara de reducir el número de militares entre los senadores de designación real, la prensa político-militar protestaría enérgicamente. «El Ejército nunca está sobrado de defensores en ninguna parte», se diría (La Correspondencia Militar, 15 de febrero de 1891).

${ }_{17}$ El Correo Militar, 3 de marzo de 1880. 
Quiere decirse que a lo largo de la Restauración se fue consolidando la idea de que el militar que accedía a las Cortes, si bien no debía su investidura parlamentaria al Ejército, se hallaba investido del carácter que imprimía la condición militar, al que no podía renunciar. Se llegaba así a concebir lo que podríamos denominar una teoría de la doble investidura del militar elegido parlamentario, que por generalización se hacía extensible al senador nato o vitalicio. En determinados momentos, entrada la década de los noventa, se quiso dar incluso prioridad a la investidura militar sobre la parlamentaria propiamente dicha ${ }^{18}$. De esta forma, la teoría de la doble investidura serviría para canalizar en gran medida planteamientos corporativistas.

La realidad, sin embargo, no correspondería a las aspiraciones castrenses. La representación política anulaba la pretendida representación profesional en los militares parlamentarios. A lo más que éstos llegaron fue a reunirse en vísperas de debatirse los presupuestos para tratar de la actitud a adoptar en relación a las cantidades asignadas a los departamentos de Guerra y Marina, lo que nunca se tradujo tampoco en una posición conjunta al respecto. $\mathrm{Ni}$ siquiera la crisis de marzo de 1895 hizo que se alcanzaran mejores resultados. Legislatura tras legislatura, la prensa militar se haría eco repetidamente de la sensación de que el Ejército quedaba huérfano en las Cámaras. Afirmaría que sólo excepcionalmente podía hablarse de casos en los que las condiciones personales de un determinado diputado o senador le hacían asumir la difícil representación militar, mientras la gran mayoría únicamente se preocupaba de representar a sus respectivos distritos, partidos y amigos ${ }^{19}$. Esta creencia

18 Tenemos una buena muestra en el artículo «Militares diputados», publicado por $E l$ Correo Militar el 5 de abril de 1894:

«Es de tal naturaleza la condición militar, que imprime carácter al que la posee: no es una investidura como la de otro funcionario cualquiera que desciende a la condición de ciudadano cuando cesa en dichas funciones; el militar es siempre y en todos casos militar, aún cuando figure como excedente o ponga sobre su uniforme la toga de legislador.

El militar elegido para representar un distrito no debe al Ejército su investidura, más a través de los pliegues de ésta se divisa otra que venía usando con orgullo, y que conserva puesta para lucirla de nuevo cuando le despojen de aquella.

Se debe, pues, en primer término al informe que desde sus primeros años aceptó con entusiasmo, y a la familia en cuyo seno ha vivido y a la cual ha de volver.

Tolerar o consentir que sobre el primero se arroje la más pequeña mancha es una cobardía.

Contribuir con su indiferencia a la ruina de la segunda es una traición.

Prescindir de aspiraciones legítimas y de compromisos personales, cuando unos y otros pugnan con aquellos principales deberes, es obligación que, al militar digno de serlo, se impone.

Esta es nuestra opinión, que de modo alguno se extiende a pedir ni aconseja a los militares diputados que hagan cierta clase de sacrificios innecesarios.

La ambición legítima, el deseo del bien propio y, en una palabra, toda aspiración personal o colectiva que, siendo honrada, en nadie censuramos, puede satisfacerse por los hombres civiles y militares, si marcha paralela con el bien del Estado; pero en éstos que tienen otro deber que cumplir, ha de armonizarse además con el bien del Ejército, que es algo así como padre amoroso a cuya sombra han crecido y con el cual ni pueden ni deben ser ingratos.»

19 En un derroche de concreción, La Correspondencia Militar de 9 de marzo de 1893 llegaría a distinguir tres categorías de diputados militares: 
contribuiría a acrecentar la paulatina insatisfacción castrense ante la labor legislativa y de control desarrollada por las Cortes, haciéndolas responsables en gran parte de las deficiencias de la organización militar española.

Algunos sectores militares de opinión se sintieron tentados en determinados momentos por las ideas corporativistas que circulaban con incierta fortuna en la sociedad española, buscando una representación directa del Ejército en las Cortes. El Correo Militar propuso que se presentara una «candidatura del Ejército» en las elecciones al Congreso de 1881. El general Manuel Cassola y sus partidarios - $\mathrm{y}$ entre ellos La Correspondencia Militar- abogaron en 1889-90 por que la nueva Ley Electoral introdujera los colegios especiales militares (del tipo de los que contemplara el artículo 24 de la Ley de 26 de junio de 1890), reivindicación que se volvería a plantear periódicamente y a la que se sumaría en 1893 El Correo Militar. A finales de 1898, La Correspondencia Militar defendería el «sufragio por gremios y clases», también para el Ejército, en la línea de las propuestas de la Asamblea de las Cámaras de Comercio de España reunida en Zaragoza. Todas estas actitudes eran en buena parte producto de la decepción de diferentes sectores militares ante la inviabilidad de la teoría de la doble investidura, decepción que se haría más palpable con el transcurso del tiempo. Incluso El Ejército Español, el único de los tres grandes periódicos militares que nunca se sumaría a las formulaciones abiertamente corporativistas (quizá por su alineamiento liberal-fusionista y a pesar de su proximidad en tiempos al programa de reformas del general Cassola), no escondió su desilusión ante la realidad de que «los militares que se honra(ban) con la investidura de diputados desaparec(ieran) para convertirse en hombres de partido» ${ }^{20}$.

\section{CRITICA DE LA EFICACIA PARLAMENTARIA}

La eficacia de. las Cortes sería medida desde el campo castrense por las soluciones legislativas que ofrecieran a la problemática militar.

Con el paso de los años, la prensa militar arreciaría en sus expresiones de desengaño ante lo que juzgaba como escaso interés de los sucesivos Gobiernos y Cortes de la Restauración por abordar la reforma de la organización militar. Rara sería la legislatura que al concluir no levantara las quejas de la opinión militar, por haber quedado pendiente la discusión o aprobación de diversos proyectos referentes al Ejército; proyectos que serían recordados sistemáticamente a los nuevos legisladores. Las páginas de los periódicos profesionales estarían plagadas de recriminaciones dirigidas a las Cortes por el exceso de oratoria y de personalismo que decían descubrir en los trabajos parlamentarios.

Es más: a pesar de las lógicas diferencias de criterio entre los periódicos

«1. Los que trabajan en favor del Ejército; 2. Los que están en condiciones de trabajar por él; $3 .^{\circ}$ Los que sirven sólo a sus distritos, a su partido y a sus amigos.» once.

Clasificaba en el primer grupo a seis diputados, en el segundo a tres y en el tercero a

${ }_{20}$ El Ejército Español, 2 de marzo de 1893. 
militares, en razón del momento político y de las simpatías partidistas, se manifestaría repetidamente entre ellos la tendencia a solicitar que, en la medida de lo posible, las reformas militares se emprendieran por vía de decreto, sin pasar por las Cámaras, cuestión esta que sería objeto de una polémica particularmente intensa con ocasión de los proyectos de Cassola $(1887-88)^{21}$. No se perdería la esperanza de que la reforma del Ejército fuera producto de una decisión gubernamental auspiciada por un ministro militar con suficiente energía como para empeñar al Gobierno en una tarea así. La experiencia cassolista, a pesar de su fracaso final, ayudaría a consolidar esta convicción. Muy demostrativa fue la recomendación que en 1890 dirigiera El Ejército Español (liberal) al ministro de la Guerra, general Azcárraga (conservador), para que se dejara de excesivos miramientos con las Cortes. Convencido el periódico de que «el Parlamento e(ra) un obstáculo imposible de salvar» para las aspiraciones militares, recordaba las palabras de Cassola: «Nunca me arrepentiré bastante de haber sido respetuoso al exceso con el poder legislativo" ${ }^{22}$. A pesar de todo, nunca dejaría la prensa militar de exigir insistentemente, aunque lo hiciera muchas veces en tono desesperanzado, la oportuna y lógica acción legislativa para alcanzar sus objetivos reformistas ${ }^{23}$.

\section{CRITICA DEL SISTEMA POLITICO}

El antiparlamentarismo de la opinión militar sigue un proceso paralelo al de crítica del sistema político.

La prensa político-militar muestra la imagen de un Ejército identificado con los fundamentos ideológicos y políticos del régimen de la Restauración: sentido sólidamente monárquico, conciencia restauracionista, convicciones liberal-burguesas, preeminencia de los conceptos de orden y legalidad, aceptación del principio de la supremacía del poder civil con un poder militar prestigiosamente institucionado... Ello no impidió que en 1887-88 la opinión militar comenzara a reprochar abiertamente al sistema político su indiferencia y hasta su incapacidad para resolver los problemas del Ejército, sin aguardar siquiera a que concluyera su etapa configuradora (1890-91).

Por otra parte, los órganos de opinión del Ejército defendían sustancialmente la fórmula del turno bipartidista, esto es, un sistema de dos partidos alternándose en el ejercicio del poder, sólidamente constituidos y comandados, que posibilitaran una enérgica política de inspiración nacional. Sin embargo,

${ }^{21}$ El Correo Militar, único periódico que se opuso a la posibilidad de que parte de los proyectos del ministro Cassola se realizaran mediante decreto, había defendido anteriormente la necesidad de plantear la reforma de la organización castrense precisamente por decreto (véase 13 de octubre de 1879,12 y 25 de febrero de 1881 y 20 de octubre de 1883, por ejemplo), opinión a la que volvería en ocasiones durante el decenio de los 90 .

${ }_{2}$ «El Ejército y las Cortes», El Ejército Español, 14 de agosto de 1890.

${ }^{23} \mathrm{La}$ defensa de los intereses militares y demás funciones asumidas por los periódicos político-militares, queda vinculada siempre a la causa de un reformismo militar sublimado. La defensa de un programa de reformas consideradas necesarias en el plano militar y el restablecimiento de un orden moral en el Ejército y en la sociedad, se liga en definitiva a una idea de «regeneración». 
la interpretación que hicieran, sobre todo en los años noventa, de la evolución política española y de sus consecuencias en el plano militar va tejiendo un entramado de convicciones antipartidistas y de inclinaciones autocráticas, al considerar dsvirtuados, ineficaces, débiles, descompuestos y, por tanto, antipatrióticos tanto el sistema de partidos como el de gobierno y el de representación política.

Así, pues, en el último decenio del siglo, dejados atrás los años de ciego fervor por la Restauración, la prenda político-militar dice continuamente constatar el creciente divorcio entre sociedad militar y sociedad política, distinguiendo en realidad un doble divorcio superpuesto:

- Los políticos y la política de partidos, de un lado, y el Ejército, la opinión militar, por otro.

- Los políticos y la política de partidos, por una parte, y la nación, la opinión del país, por otra.

La insatisfacción militar apunta directa y principalmente contra los políticos, contra la clase política; las citas que podrían sacarse a colación son casi infinitas, en todos los tonos y formas ${ }^{24}$. $Y$ como es en los escaños de las Cortes donde la clase política encuentra su ubicación natural, el antiparlamentarismo resulta efecto obligado prácticamente.

Señalaremos, sin embargo, que lo que la prensa militar expresa con su fobia hacia los políticos no es apoliticismo (puesto que asume la politización institucional del Ejército de la Restauración y participa de ella) ni tampoco antipoliticismo (propio de posiciones anarquistas), sino antipartidismo, condensado ejemplarmente en la frase: «Hay que entrar en la política... ipara acabar con ella! ${ }^{25}$. Por política se entendía la política de partidos ${ }^{26}$.

${ }^{24}$ Veamos algunas:

«... Hoy ante Europa somos un guiñapo; un desprecio.

... Gracias a esa turba de políticos sin conciencia que nos deshonran y saquean; gracias a todos, desde los que militan en el campo del absolutismo hasta los federales con ribetes socialistas. Todos son uno... Por excepción entre ellos parece alguno libre de mácula, y ese como regla general, lo que posee de honradez nativa, fáltale de viveza y le sobra de cándidas filosofías" (El Correo Militar, 20 de diciembre de 1893).

«Si el antiguo uso de estampar cada hombre en su escudo el lema más apropiado a sus gustos e intenciones se hallase de moda, ninguno más característico para todos (excepción hecha de dos o tres) los políticos que hoy figuran en los partidos españoles que aquel famoso del estandarte de Francisco I de Francia: Nutrisco et extinguo, me alimento y extingo» (El Ejército Español, 23 de enero de 1890).

«De una cosa puede estar convencido el Ejército; de que los políticos españoles no lo entienden; no se preocupan siquiera de él, como no sea para hacerle daño, sino cuando le tienen miedo; cuando creen que de sus actos depende el curso de la vida pública» (La Correspondencia Militar, 16 de enero de 1892).

${ }_{25}$ «Morir por las propias armas», La Correspondencia Militar, 7 de diciembre de 1892.

${ }^{26}$ Hagamos constar que la prensa político-militar vino a debatirse, cada vez más a meclida que tocaba a su fin el siglo xIx, en la contradicción, claramente condicionante, entre apartidismo teórico (su cobertura de postulados formales meramente profesionales), antipartidismo político de respuesta (sus tesis ante la evolución política española de los años 90) y partidismo práctico (su alineación periodística con posiciones de partido). 


\section{LAS COTAS DIFICILMENTE REVERSIBLES}

La fecha puntual de despegue del antiparlamentarismo de la prensa militar puede situarse en 1887-88, coincidiendo - no por casualidad - con el debate del programa de reformas militares del general Cassola, y sería el decenio de los noventa el que conociera la intensificación del fenómeno. El recelo militar hacia las Cortes, que siempre había levantado el tema de los presupuestos de los departamentos de Guerra y Marina, habitualmente considerados escasos en medios castrenses, pasaría a convertirse en franca hostilidad con motivo de la aplicación de los planes de economías y del odiado «presupuesto de paz» (1891-92). Con las crisis bélicas de Melilla, Cuba y Filipinas, el antiparlamentarismo militar se vería definitivamente espoleado.

Por regla general, el antiparlamentarismo del periódico militar se intensifica a medida que éste se aleja políticamente del partido en el Gobierno y asimismo cuando se distancia de la corriente mayoritaria del partido que atrae sus simpatías. Este último fenómeno se aprecia claramente, por ejemplo, tanto en el caso de El Correo Militar, a medida que Silvela gana posiciones en el partido conservador tras la muerte de Cánovas como en el de La Correspondencia Militar, cuando su cassolismo le lleva a enfrentarse con Sagasta, e igualmente en el de El Ejército Español, cuando en repetidas ocasiones a lo largo del último lustro del siglo pasado reprocha al fusionismo su actuación en el campo político o militar.

Todos los periódicos militares vertían sobre las Cortes, simultáneamente o en momentos diferentes, los más agrios adjetivos: «decadentes», «inútiles», «viciadas», «estériles»... Tampoco dejarían de añorar a veces la actuación del general Pavía en $1874^{27}$. Hasta El Correo Militar, único periódico profesional que en marzo de 1893 defendiera que la nueva división territorial militar debía hacerse contando con las Cortes, era capaz de emitir por aquellas mismas fechas afirmaciones tan desfavorables para ellas como la siguiente: «Las Cortes futuras, como todas las que a nuestra vista van pasando, nada harán por levantar a España de su actual postración ${ }^{28}$.

La prensa político-militar apuntaba con su razonamiento, pues, a que las Cortes se olvidaban de las necesidades de la institución militar, de la misma forma que se olvidaban de las verdaderas necesidades de la nación, sin que hubiera justificación para ello, mucho más cuando en el periodismo militar había superado ya su fase configuradora, lo que le permitía abandonar los trabajos legislativos de carácter eminentemente político ${ }^{29}$.

${ }^{27}$ Basta consultar los comentarios de los periódicos militares casi todos los del 3 de enero, conmemorando la efemérides protagonizada por Pavía.

${ }^{28}$ El Correo Militar, 7 de marzo de 1893.

${ }^{2}$ El artículo que revelará con mayor claridad esta conciencia de que se había cerrado ya el ciclo configurador de la Restauración sería el que, bajo el título de «El Ejército y las nuevas Cortes», publicara La Correspondencia Militar el 4 de febrero de 1891, como puede verse:

«... En el período revolucionario, por ejemplo, absorbía a todos la discusión de grandes principios que apasionaban los ánimos, enardeciendo a la vez toda suerte de pasiones. En los primeros años de la Restauración sucedía cosa análoga y aún 
Los propios periódicos militares nos confiesan su poca fe en el' sistema parlamentario, especialmente en el último decenio de $\operatorname{siglo~}^{30}$. Se consolida así

hasta el día ha podido decirse que ocupaban lugar preferente las cuestiones políticas sobre todas las restantes, por no hallarse cerrado aún el período constituyente.

Hoy ni esa disculpa tienen las Cámaras para descuidar los verdaderos intereses del país, los problemas militares, económicos y administrativos y aún el arduo problema social; hoy en el orden político, puede decirse que todo está hecho, al menos dentro del régimen monárquico constitucional vigente; hoy, hasta por el propio reposo del país, conviene que durante algunos años no hagan las Cortes una sola ley de carácter político, limitándose a gobernar los partidos con las que rigen, que interpretadas con amplio sentido, cumplidas con rigor, son tan liberales como las corrientes de la época imponen.»

${ }^{30} \mathrm{He}$ aquí cómo se expresaba El Correo Militar el 26 de abril de 1893:

«Existe una verdadera antítesis; una repulsión moral entre el Ejército y el parlamentarismo.

El parlamentarismo es el sistema constitucional parlamentario, lo que el militarismo a la fortaleza militar de las naciones.

Un pueblo puede poseer una vigorosa organización militar sin hallarse sometido al régimen del militarismo; así como es posible que bajo tal régimen sea en extremo débil su poder militar.

$Y$ a la vez, los pueblos en que el sistema constitucional posea vigor y arraigo, estarán más lejos que ningún otro de lo que llamamos hoy parlamentarismo.

El militarismo (que entre paréntesis no ha existido nunca en España) es el usufructo del poder por una clase del Estado; por los militares.

El parlamentarismo (que en España sí que existe) significa el ejercicio del poder por otra clase del Estado; por los hombres que hacen de la política oficio provechoso.

(...)

Con ser grave el hecho de que todas las corrientes tiendan a artastrar el parlamentarismo a donde van los «detritus» sociales, hay algo de mayor gravedad: la carencia de fórmulas, de recursos para sustituir el sistema, bueno en sí, a que como hiedra se ha adherido, corrompiéndolo y ahogándolo.»

En 1898, el 28 de marzo, este mismo periódico emprendería ya un ataque en toda regla contra el sistema parlamentario:

« $\mathrm{Y}$ no es que sintamos ansias y dolores ante el fracaso del parlamentarismo, hecho no exclusivo de España hoy, sino de todos los países que disfrutan de tal sistema, y aún de aquellos en que según sucede en la República norteamericana, lo que existe es el sistema representativo. Corrupción en todas partes es lo que se contempla. Sólo en la Gran Bretaña y en Suiza es donde, por circunstancias especiales, no se da semejante espectáculo. A nuestro juicio, y sin que nos metamos a definir lo antiguo ni a propagar nada nuevo, el origen de cuanto pasa nace sólo de un error capital de los grandes teorizadores políticos; los cuales, al dar a las naciones leyes todo lo perfectas posible, se olvidaron de hacer antes los hombres que las habían de usar.

(...)

Con un Parlamento cuya autoridad no procediese de una ficción constitucional, más o menos conveniente y aún necesaria, pero ficción al fin, sino que representase con fidelidad absoluta la voluntad de todos los españoles, el problema indicado no existiría para el Ejército. La nación soberana de sí misma puede hasta suicidarse si así lo quiere y decide, más no sucede lo mismo si esa resolución, y aún otras de menor gravedad, es adoptada por unos cuantos hombres cuya autoridad tiene por origen el encasillado del Ministerio de la Gobernación, y el apoyo de los caciques rurales, con su séquito de abusos y trapisondas, todo ello condensado en el voto, no de la inmensa mayoría de los españoles, sino del escaso número de ciudadanos que por buenas o por malas moléstase en llevar su papeleta a las urnas.»

La Correspondencia Militar adoptaría actitudes inequívocas, como se desprende de los siguientes párrafos, publicados el 25 de abril de 1890 : 
una proclividad antiparlamentaria dirigida normalmente contra el legislativo español de aquel tiempo, pero que no deja de plantear la inconveniencia política de las instituciones parlamentarias en general. Fue un hecho que el antiparlamentarismo de un periódico militar se apagara cuando su director resultaba elegido diputado. Así ocurrió cuando El Correo Militar estuvo dirigido por el diputado conservador Francisco Javier Ugarte y Pagés (octubre 1892 marzo 1893) y mientras el director de La Correspondencia Militar, Diego Fernández Arias, ocupó un escaño en el Congreso (marzo 1896-febrero 1898). Pero sólo eran treguas que se autoimponía el periódico en cuestión y no cambios sustanciales de convicciones.

La ola de «regeneracionismo» que sacude a la sociedad española tras la derrota colonial del 98 afectó igualmente al Ejército. La prensa militar aviva su crítica contra el sistema de representación política vigente y pasa a sugerir diversas fórmulas correctoras. o compensadoras. El Correo Militar propone como única solución viable «compaginar los trabajos electorales con la acción eficaz, en el sentido de protectora del sufragio, de la autoridad militar» ${ }^{31}$. La Correspondencia Militar se apunta por su parte a la corriente favorable a la representación corporativa en Cortes ${ }^{32}$. El Ejército Español insiste en la idea de que las medidas regeneradoras no pueden venir de mano de las Cortes y propone «un interregno parlamentario para sentar la base de la reorganización radicalísima que exige el estado del país» ${ }^{33}$.

«Que nuestras campañas se dirigen a desprestigiar el sistema parlamentario, dice El Correo, y a fe que no acierta. Por una razón muy sencilla, por la de que si ese sistema conservara sus prestigios, antes procuraríamos mantenerlos que combatirlos; pero como no puede estar ya más desprestigiado, no son precisas campañas nuestras ni de nadie para tal objeto.

Lo que hacemos es sencillamente decir la verdad; a sernos posible hoy, como quizá lo sea algún día, exigiríamos estrecha responsabilidad a los causantes de ese desprestigio; a los hombres que al nacer en España aquel régimen, que de conservarse puro sería el más propio para las sociedades presentes, lo han viciado en su origen trayéndonos el tremendo estado de cosas actual.»

Por su parte, El Ejército Español dejaba sentada su posición el 24 de junio de 1893 :

«Tiempo hace, mucho tiempo, que nosotros perdimos ya las ilusiones respecto a él (el sistema parlamentario), y rectificamos antiguas opiniones creadas al calor de la idea, cuạndo aún no habían empañado su deslumbrante brillo las impurezas de la realidad...»

El mismo periódico tampoco daría lugar a dudas en su número del 24 de junio de 1898:

«¿Qué representa hoy el Parlamento para el país? Pudo ser mucho; pudo ser el áncora de su salvación; pudo, fundiéndose todas sus fracciones en un mismo sentimiento de amor propio, elevarse a la altura de las circunstancias y ser el alma misma de la nación enfrente de la guerra inicuamente provocada por los Estados Unidos. En vez de esto, se ha limitado a desempeñar el mismo papel que de muy antiguo ya viene desempeñando en la política española. Discusiones pequeñas, ruines; debates animados en los cuales no se buscan recursos para la crisis económica ni alivio para la social, ni se adoptan medidas enérgicas ni determinaciones viriles que puedan sacar al país de su situación actual, si no con provecho, al menos con honor; charlas inútiles, en vez de esto, en las cuales sólo se trata de poner en claro los errores, las deficiencias, cuando no hay nadie que esté libre de pecado.»

31 Véase El Correo Militar, 10 de diciembre de 1898.

${ }^{32}$ Véase La Correspondencia Militar, 1, 9 y 19 de diciembre de 1898.

33 Véase El Ejército Español, 13 de diciembre de 1898. 
IMPLICACIONES PARA EL SISTEMA DE LA DOBLE CONFIANZA.

\section{LA LEGITIMIDAD MILITAR-POPULAR}

Las argumentaciones a través de las cuales tomaba forma el antiparlamentarismo militar alcanzaban políticamente muy lejos. Comportaban poner en duda, expresa o tácitamente, el llamado sistema de la doble confianza, pieza fundamental de la construcción jurídico-política del régimen de la Restauración.

Partiendo de unas elecciones y unas Cortes a las que se criticaba su viciosa incapacidad para derribar Gobiernos, de unas Cámaras a las que por diversos motivos se les negaba carácter verdaderamente representativo, el razonamiento de la prensa militar pulverizaba el esquema de la doble confianza; la única confianza efectiva con la que tenía que contar un Gobierno era la de la Corona. Era la voluntad real y nunca la de las Cortes — seguía pensando la opinión militar - la que resolvía las crisis de Gobierno, aunque para ello tuviera que llamar al poder al partido que estaba en minoría en las Cámaras y desposeer de él al que contaba con una aplastante mayoría ${ }^{34}$. Bastaba el decreto de disolución y la celebración de nuevas elecciones para que las Cortes aceptaran sin grandes dificultades los dictados gubernamentales de turno ${ }^{35}$. Consciente de ello, la prensa militar reclamaría en ocasiones la intervención directa de la Corona para que forzara el relevo del Gobierno ${ }^{36}$.

Siguiendo este hilo argumental, a la representación parlamentaria se la consideraba en la práctica poco menos que una ficción. ¿Qué pasaría entonces si surgiera el conflicto entre la Corona y las Cámaras, visto que éstas no podrían recabar obediencia a título de ser la legítima representación nacional? ¿Qué haría el Ejército en tal caso? La posibilidad de un conflicto de este tipo apenas se plantearía en las columnas de la prensa militar entre 1875 y 1898 , pero cuando surgió el tema fue para apuntar que su resolución sería desfavorable para las Cortes ${ }^{37}$. Aquello reforzaba los lazos de origen estamental que unían de forma peculiar al Ejército con el rey ${ }^{38}$.

En el desprestigio del Parlamento y en la invalidación de la doble confianza radicaría el motivo de que en ciertos momentos se produjera la apelación militar a la opinión del país.

${ }^{34}$ Véase «El deber del Ejército», La Correspondencia Militar, 5 de julio de 1889, en donde se apostillaba: «Lo cual prueba que esos mismos poderes públicos no creían en que esa mayoría representase la voluntad del país, pues de ser así no se hubieran atrevido a contradecirla,»

${ }^{35}$ Durante un tiempo (1890-1891) algunos periódicos militares - La Correspondencia Militar y El Ejército Españal- insistieron en la idea de qué se podía esperar de un sistema en el que bastaba una "corazonada» para que cayera el Gobierno. Se referían, claro está, a la conocida como la «corazonada» de Martínez Campos en el horizonte de la crisis gubernamental de junio-julio de 1890 .

${ }^{36}$ Uno de los artículos más directos en este sentido fue el titulado «El tiempo apremia», publicado por La Correspondencia Militar el 29 de agosto de 1893.

${ }^{37}$ Especialmente espectacular en el planteamiento de este tema fue el artículo titulado «El día de ayer», de El Correo Militar de 28 de marzo de 1898.

${ }_{38}$ Desde luego, para el Ejército de la Restauración, su relación con el rey sería prioritaria políticamente a todos los efectos. Ya decía Max Weber, refiriéndose al Ejército, que «primitivamente se trataba de un estamento profesional determinado por la forma de relación con el soberano» (Economía y sociedad, F. C. E., México, 1964, pág. 247). 
«No basta que la Corona y el presidente del Consejo de Ministros quieran que siga gobernando el partido (en el poder)... y mucho menos su jefe...; es preciso que se tenga en cuenta la opinión del país, dígase lo que se quiera de la conciencia que éste tiene de sus derechos» ${ }^{39}$.

No se trataba de ninguna pretensión plebiscitaria en definitiva -aunque alguna vez pasara como tal-, habida cuenta de que en otros momentos los periódicos militares demostrarían, en mayor o menor medida, inequívocas actitudes doctrinarias, de menosprecio o temor hacia el protagonismo político de las masas ${ }^{40}$. Detrás de aquellas palabras subyacía el pensamiento de que si fallaban los mecanismos político-parlamentarios de representación de la opinión del país, esta representación debía ser asumida por aquellas instituciones íntegras y leales al conjunto de la nación, y el Ejército pensaba que ninguna más cualificada que él mismo.

«El Ejército es el órgano por donde manifiesta el país su opinión, a falta de otro que no esté viciado, que no sea corrompido. Aquí, donde el poder alcanza siempre inmensa mayoría en los comicios, cualesquiera que sean el sistema que se siga o la ley con que se gobierne, aquí, donde el poder tiene en sus manos los resortes todos de la gobernación y no deja ninguno al pueblo, el Ejército se hace intérprete y ejecutor, al mismo tiempo, de los designios populares: recibe su inspiración y obra en vista de ella» ${ }^{41}$.

La institución armada se veía a sí misma como eminentemente popular, sincronizada con el latir de la opinión nacional y plenamente capaz de interpretar las aspiraciones de la gran mayoría de españoles. Esta concepción del Ejército se halló siempre presente de alguna forma en los contenidos de la prensa político-militar a lo largo del último cuarto del siglo xIX. Con ello pretendía identificar su opinión no sólo con la del colectivo militar, sino con la del conjunto de ciudadanos. Sus críticas, sus argumentaciones, sus propuestas, tendían a presentarse como si estuvieran respaldadas por la opinión militar y por la opinión pública, la de la nación. Se construye así un teórico puente veneciano por encima de las instituciones de representación parlamentaria. Y al tiempo que se elabora esa ficción, se reclama con fuerza la reforma del sistema de poder.

Precisamente de toda esta concepción surgía la convicción castrense de que todo cambio político había de contar con el respaldo militar-popular (más

39 «El juego político», La Correspondencia Militar, 2 de julio de 1890.

40 Significativamente, el periódico militar que se distingue entre los de su clase como el más populista, La Correspondencia Militar, llegaba a realizar afirmaciones como las siguientes («La razón de la sin razón», 21 de diciembre de 1895):

«Quitad el bozal al pueblo y veréis un tigre. La crudeza que a esta frase de Napoleón dan las palabras bozal y tigre no desvirtúa en nada su fondo de verdad en estos tiempos de libertad y democracia, señoras que, a juzgar por lo que en la carrera se prodigan y desmandan, van haciéndose ya demasiado sospechosas.

Es lo cierto que, frente al pueblo soberano, se pasea también mucha canalla...»

${ }^{41}$ El Ejército Español, 3 de enero de 1894. 
exacto sería decir «militar-nacional»), es decir, debía buscar su legitimidad en lo que se entendía era el tradicional consenso del Ejército y la nación.

Desde la prensa político-militar se creaba directa o indirectamente un clima, una disposición, favorable a la intervención del Ejército en política, más allá de los límites marcados por el régimen de la Restauración. El antiparlamentarismo de la opinión militar iría unido inevitablemente a la creencia en lo que S. E. Finer llamara «el destino manifiesto de los militares» ${ }^{42}$, esto es, en que la historia tenía reservado al Ejército español el destino de salvar repetidamente a la nación, lo cual se entendía apoyado por la experiencia intervencionista del Ejército isabelino, a la que formalmente, sin embargo, no se quería volver. Pero éste es ya otro tema que sólo apuntamos.

Como puede verse, el enfrentamiento entre la opinión militar española y las Cortes tendría otras vertientes y muchos más matices de los que se han tratado. Nos hemos centrado aquí en los aspectos más político-históricos del antiparlamentarismo militar de la primera mitad de la Restauración, los elementos de partida en la formación de las actitudes del Ejército español en el siglo $\mathrm{xx}$, aunque algunos de ellos se hubieran ya manifestado en etapas anteriores de nuestra historia. No hacemos referencia, pues, a la incidencia de los aspectos estructurales de la corporación estamental militar: la del sistema de valores y creencias y la de las formas de organización y cohesión profesional del colectivo castrense, ambas muy peculiares y de importante alcance ideológico.

Sí queremos que quede claro que las actitudes antiparlamentarias del Ejército español se configuran básicamente y se manifiestan ya sin reparos, con anterioridad a que el sistema político de la Restauración entre en crisis, si nos atenemos a las fechas que sobre ésta se señalan convencionalmente. Pero ¿cuándo se produjo en realidad esa crisis? Es algo que hay que replantear. Puesto que el Ejército estaba destinado a ser al cabo de los años el verdugo de aquel sistema político, a la hora de analizar el proceso que sigue la crisis de la Restauración debería contarse más con la importancia de la opinión y las actitudes del colectivo militar y con sus interpretaciones al respecto. Ojalá que las anteriores páginas contribuyan en algo a esa difícil tarea.

${ }^{42}$ Los militares en la política mundial, Editorial Sudamericana, Buenos Aires, 1969, páginas 48 y sigs. 